analecta polit. | Vol. 11 | No. 20 | PP. 1-5 | enero-junio | 2021 | ISSN-e: 2390-0067 (en línea) | Medellín-Colombia doi: https://doi.org/10.18566/apolit.v11n20.a00

\title{
Editorial \\ Colombia: tres décadas de vigencia de la Constitución Política de 1991
}

Colombia: three decades of effect of the Political Constitution of 1991

JAVIER DUQUE DAZA

Universidad del Valle, Colombia jduqued86@hotmail.com 
En Colombia, se cumplen este año tres décadas de vigencia de la Constitución Política de 1991. El nuevo arreglo institucional fue la expresión de un cambio discontinuo en una coyuntura crítica que produjo una fuerte ruptura con el pasado.

La nueva y extensa Constitución (380 artículos y 67 transitorios) incluyó normas para su modificación formalmente intrincadas. No obstante, en estas tres décadas, han sido frecuentes las reformas y cada inquilino de la Casa de Nariño y sus socios partidistas del momento han impulsado y concretado los cambios que han querido. Con excepción del año en que se estrenó (1992), todos los años se ha cambiado la Constitución. La vía del cambio ha sido la transacción entre mayorías fabricadas. Los ciudadanos han estado ausentes.

Después de la vigencia durante más de un siglo de la Constitución Política de 1886 y del congelamiento de las normas en las tres décadas que la antecedieron, en 1991, se aprobó una nueva carta magna en Colombia que lo cambió casi todo. Este proceso tuvo cuatro características centrales.

Primero, se dio en una coyuntura crítica. El país pasaba por un periodo de álgida violencia política que afectaba a líderes políticos de izquierda y de los propios partidos Liberal y Conservador. Había frecuentes expresiones de descontento social, arreciaba el terrorismo de los carteles del narcotráfico y múltiples formas de criminalidad hacían de Colombia el país más violento del planeta.

Segundo, fue un cambio por negociación. En contraste con el predominio histórico exclusivo de los partidos Liberal y Conservador, en la Asamblea Nacional Constituyente (ANC) participaron diversas organizaciones políticas y partidistas, y ninguna de ellas logró obtener mayoría suficiente para imponer decisiones. Se impuso la vía de las negociaciones incluyentes y de las coaliciones.

Tercero, la conformación pluralista de la ANC hizo que se moderaran las posiciones duras. Los sectores de izquierda que accedieron a la ANC asumieron cierto pragmatismo al abordar problemas como la propiedad privada y la fuerza pública, mientras sectores de derecha moderaron sus posiciones en temas de contenido social.

Cuarto, hicieron presencia en la ANC representantes de grupos indígenas y de movimientos religiosos no católicos, tradicionalmente excluidos de los procesos de toma de decisiones, de igual forma que exguerrilleros del M-19 y otros grupos desmovilizados. 
La composición multipartidista y plural de la ANC y la lógica de las negociaciones se reflejaron en el contenido y en la orientación de la nueva carta. Aunque se mantuvieron algunas constantes como el presidencialismo, el bicameralismo y la representación proporcional, se estableció una nueva arquitectura institucional con nuevas reglas de juego en todas las áreas de la sociedad.

La Constitución que costó tantos esfuerzos, intentos fallidos, debates y tortuosos acuerdos ha perdurado poco. Los sucesivos gobiernos y congresos se han dedicado a cambiarla y en tres décadas se ha reformado 52 veces, una reforma cada 7 meses. Los colombianos buscamos y buscamos y no logramos acordar reglas estables. Hay mucha inestabilidad, intereses particulares y de grupo que se reflejan en los constantes cambios y en una larga tradición de fetichismo jurídico que asume que los problemas se arreglan con nuevas reglas, sin pensar mucho en los demás factores que hacen tan difícil la convivencia en nuestra sociedad.

Todas las reformas han sido a través del Congreso. Solo se ha aprobado, convocado y votado un referendo para reformar la Constitución, en 2003, durante el Gobierno de Álvaro Uribe Vélez. Fue un fracaso total, pues solo se aprobó uno de los 18 artículos que incluía. Aunque se han presentado varios proyectos para convocar una asamblea constituyente, todos han fracasado.

Tabla 1. Reformas constitucionales en cada Gobierno (1992-2020)

\begin{tabular}{ccc}
\hline Gobierno & Periodo & Reformas constitucionales \\
\hline César Gaviria Trujillo & $1990-1994$ & 3 \\
\hline Ernesto Samper Pizano & $1994-1998$ & 4 \\
\hline Andrés Pastrana Arango & $1998-2002$ & 7 \\
\hline Álvaro Uribe Vélez & $2002-2006$ & 8 \\
\hline Álvaro Uribe Vélez & $2006-2010$ & 6 \\
\hline Juan Manuel Santos & $2010-2014$ & 10 \\
\hline Juan Manuel Santos & $2014-2018$ & 7 \\
\hline Iván Duque Márquez & $2018-2020$ & \\
\hline
\end{tabular}

*Solo incluye los dos primeros años y cinco meses de gobierno, desde agosto de 2018. Fuente: elaboración propia a partir del Congreso de la República, actos legislativos.

La rigidez formal que se supone que hace difícil cambiar la Constitución se convierte en alta flexibilidad debido a la presencia de gobiernos unificados mediante coaliciones fabricadas. Aunque en Colombia no existen partidos con capacidad de conformar gobiernos unificados solo con sus propios escaños, sí se 
fabrican mayorías mediante coaliciones agregando apoyos partidistas a través de la distribución de incentivos selectivos con recursos estatales.

Esto ha sucedido especialmente con los gobiernos que más reformas han adelantado con éxito. Álvaro Uribe Vélez logró mantener una amplia coalición en sus dos periodos de gobierno (2002-2006 y 2006-2010) mediante la distribución de incentivos selectivos, y en sus ocho años de mandato se aprobaron 14 reformas a la carta, incluida la reforma de la Constitución que aprobó la reelección presidencial (Acto legislativo 1 de 2005) que fue ampliamente cuestionada y condujo a tres ministros a la cárcel; el secretario de la Presidencia y dos congresistas también fueron condenados por el delito de cohecho. Salió costosa la reforma, no solo para ellos, sino también para el país que entró en una dinámica de polarización y pérdida de legitimidad del poder político de graves consecuencias.

También Juan Manuel Santos mantuvo durante sus dos periodos (2010-2014 y 2014-2018) una coalición mayoritaria mediante distribución de incentivos a los congresistas. A esta coalición se sumaron los partidos de izquierda cuando se aprobaron las reformas relacionadas con el proceso de paz con las Fuerzas Arma-das Revolucionarias de Colombia (FARC) que se concretó en los acuerdos de La Habana (2016). Es el Gobierno que más reformas ha hecho a la Constitución. De nuevo: polarización, cuestionamientos y disputas partidistas y personales entre los dirigentes políticos. Todo esto trasladado a la sociedad.

Cada Gobierno parece ponerse como meta superar al anterior en el número de reformas. El Gobierno de Iván Duque Márquez ha logrado sumar mayorías fabricadas con partidos de heterogéneo origen y ha mantenido también el ritmo de reformas: en menos de tres años, ha cambiado la Constitución siete veces, aun estando en pandemia con un Congreso sesionando de forma virtual. Relativa-mente, puede llegar a ser el Gobierno con más cambios en menor tiempo.

La Constitución Política de 1991 ha sido reivindicada como un cambio ins-titucional realizado en una coyuntura crítica a través de la negociación y concer-tación entre múltiples actores. Se trata de un cambio desde abajo (estudiantes, organizaciones sociales, sectores políticos alternos), al cual se sumaron los de arri-ba (políticos y líderes del bipartidismo y el establecimiento) realizado mediante una ANC elegida popularmente y con una composición pluralista e incluyente.

Lo contrario ha sucedido con los numerosos cambios que se han hecho en sus tres décadas de vigencia, todos los ha realizado el Congreso: minorías que pactan 
los cambios de forma excluyente y logrados a través de la fuerza suficiente de coaliciones derivadas de pactos entre líderes partidistas.

Una evaluación en profundidad de las reformas podría orientarse a la búsqueda de aquellas que han contado con un amplio consenso entre partidos de Gobierno y oposición. Por esta vía, podría pensarse en la posibilidad de que las normas expresen lo que la sociedad realmente desea y no lo que los políticos negocian. 